\title{
Oficina de teatro de rua utilizando a literatura de cordel: um olhar-fazer etnográfico sobre a pedagogia teatral do grupo Imbuaça
}

\author{
NARCISO TELLES
}




\section{- RESUMO}

O presente artigo é uma etnografia da oficina de teatro de rua do Grupo Imbuaça. Aqui apresentamos e discutimos a partir desta experiência artístico-pedagógica, as relações entre as atividades e a linguagem de teatro popular do Grupo.

\section{- PALAVRAS-CHAVE}

Pedagogia do teatro, teatro popular, Grupo Imbuaça, etnografia.

\section{- ABSTRACT}

This paper is an ethnographic approach of the Group Imbuaça street theater workshop. As an active member of this artistic-pedagogical experience, we present and discuss the relationships between the activities of the workshop and the popular theater language of the group.

\section{- KEYWORDS}

Pedagogy of theater, popular theater, Imbuaça Group, ethnography.

Cultura popular não se conceitua, enfrenta-se. É algo que precisa ser contextualizado e pensado a partir de alguma experiência social e cultural, seja no passado ou no presente; na documentação histórica ou na sala de aula (ABREU, 2003, p. 95).

O pensar/fazer/ensinar teatro de rua com base em conteúdos presentes na cultura popular brasileira é a linha de trabalho de um dos mais antigos e importantes grupos brasileiros: o Imbuaça.

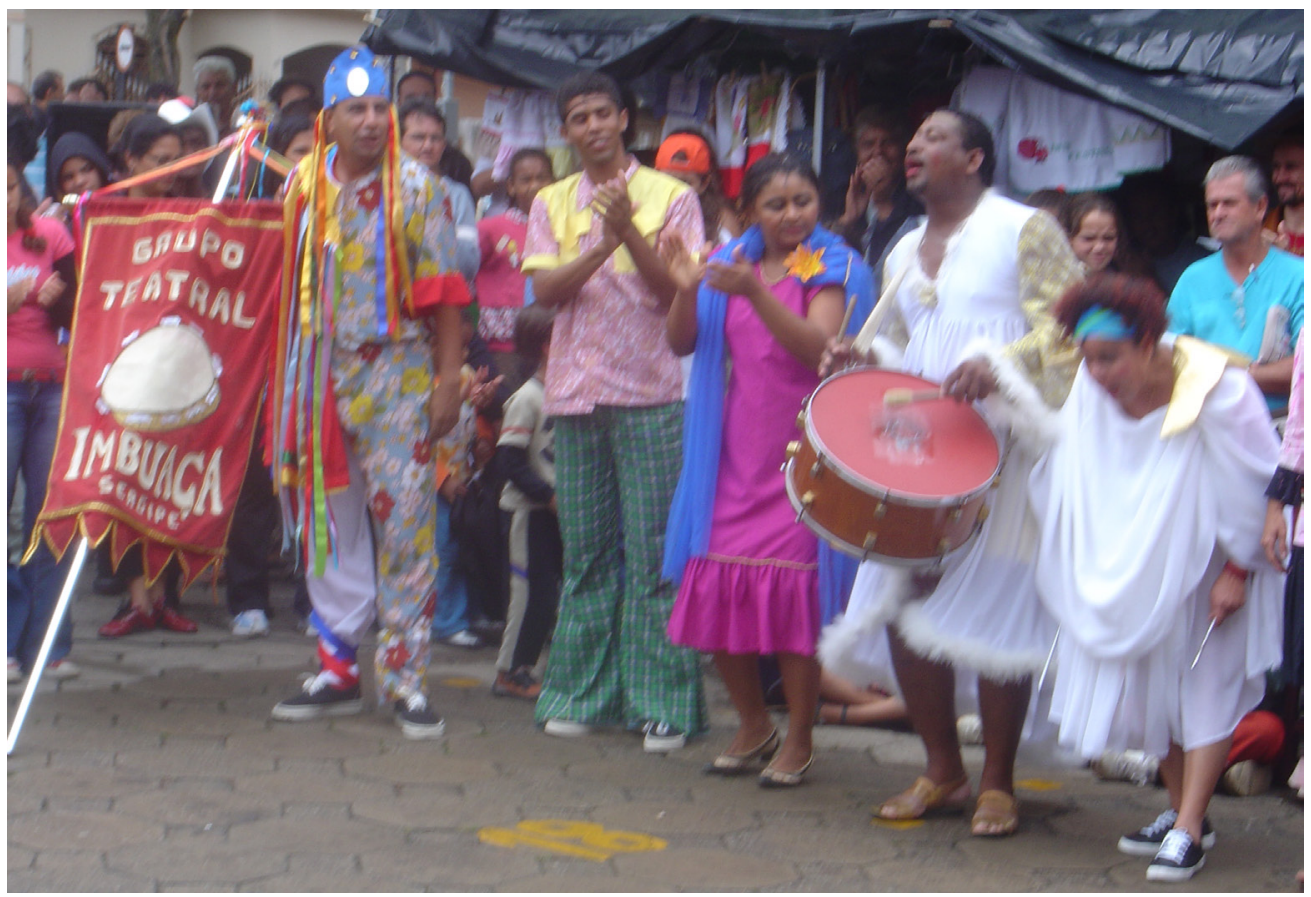

Figura 1 - Agradecimentos: Final do espetáculo de rua Teatro chamado Cordel. Grupo Imbuaça. (10/11/05). Local: Praça Itaúna, Minas Gerais. Fonte: Foto de Narciso Telles. 
O Grupo Imbuaça, sediado na cidade de Aracaju, Sergipe, foi fundado no dia 28 de agosto de 1977. Seu nome faz uma homenagem ao artista popular Mané Imbuaça $^{1}$, e, segundo seus membros, deve ser uma corruptela de imbruaca, que significa briga, confusão. Sua trajetória artística tem trilha do um caminho estético intrinsecamente vinculado à cultura popular tradicional nordestina, especialmente a sergipana, configurando uma proposta teatral de rua relacionada ao chamado teatro popular. Segundo o ator Lindolfo Amaral, a identidade do grupo está fundamentada nestes elementos: "A fundamentação do trabalho do Imbuaça está na cultura popular. É a partir de alguns elementos, que nós chamamos elementos da cultura popular, que estabelecemos a base para a construção de nosso trabalho"2.

Esses elementos da cultura popular, mencionados por Lindolfo Amaral Filho (2005), são explicitados em sua dissertação de mestrado, quando afirma:

as danças e músicas do folclore sergipano fazem a base de [nossas] ações, enquanto a literatura de cordel é objeto de estudo para a construção da dramaturgia, cuja aprendizagem se deu a partir do Teatro Livre da Bahia, mais precisamente servindo-se das adaptações desenvolvidas por João Augusto (AMARAL FILHO, 2005, p. 149).

A pesquisa etnográfica descrita neste artigo foi realizada durante o Festival de Teatro de Itaúna, Minas Gerais. Neste evento, o grupo desenvolveu duas atividades: uma apresentação do espetáculo "Um teatro chamado cordel", na Praça do Mercado, e a oficina de teatro de rua através da literatura de cordel.

\section{Oficina de teatro de rua utilizando a literatura de cordel}

Nas fontes acionadas, localizamos a proposta dessa oficina:

A oficina oferece a possibilidade de percepção, por parte dos alunos, da riqueza e da diversidade da literatura de cordel, além do seu aproveitamento como material dramático. Trabalhará também a riqueza da cultura popular de Itaúna e região. A oficina poderá contribuir para o aprofundamento do debate das experiências já existentes e servir de estímulo ao surgimento de outros grupos de teatro de rua. A metodologia utilizada pelo grupo parte do referencial e do universo cultural que cada um possui. No primeiro contato serão desenvolvidos jogos de interação para que se possa conhecer a formação dos alunos. Em seguida constroem-se um repertório de atividades para ações subseqüentes. Portanto, haverá atividades no campo de conhecimento teórico e uma prática envolvendo ações físicas e atividades artísticas (PREFEITURA MUNICIPAL DE ITAÚNA, SECRETARIA DE CULTURA, MG, 2005).

A oficina, em seu primeiro encontro (12/11/05), foi iniciada com a presença de todos os membros do Imbuaça, que fizeram uma breve explanação sobre o trabalho a ser desenvolvido nos encontros e apresentaram um histórico da trajetória do grupo e seu modo de organização. Para um maior aprofundamento, Lindolfo Amaral, um dos atores do grupo, indicou aos presentes o seu artigo publicado no livro "Teatro de

\footnotetext{
1 Embolador que o grupo conheceu em fevereiro de 1978, que foi assassinado na Praia Atalaia.

2 Entrevista realizada por Narciso Telles com Lindolfo Amaral, Itaúna, 2005. 
rua: olhares e perspectivas". Após a fala do Imbuaça, todos os alunos se apresentaram. Era um público diversificado com atores jovens da cidade e da região de Belo Horizonte. Durante a explanação do trabalho, o grupo ressaltou a importância da troca de informações culturais entre os participantes e manifestou o desejo de terminar o trabalho sabendo, pelo menos, uma música do folclore da região.

Depois desse introito, o comando da oficina passou para as mãos de Iradilson Bispo. Isabel Santos Neves e José Antonio (Tonhão) Santos foram responsáveis pelo módulo "corpo e ritmo". Iradilson conduziu todo o trabalho corporal tendo como base as danças dramáticas populares sergipanas, especialmente o reisado e o guerreiro. $\mathrm{A}$ sequência de exercícios em roda, para a apreensão do movimento correto da dança, foi seguida de diagonais para a execução dos mesmos, em grupo. Tal bateria de atividades colocou o corpo em prontidão, inteiramente aquecido e preparado para o trabalho.

Todos aquecidos, iniciamos, com o comando de Isabel e Tonhão, o trabalho de ritmo e movimento. Foram formadas duas filas, seguindo a convenção das danças do guerreiro e do reisado, e iniciamos o aprendizado dos passos através do ritmo marcado pela zabumba de Tonhão e o triângulo de Isabel. Ao mesmo tempo em que dançávamos aprendíamos as músicas, num processo uno de corpo e voz. Os passos do guerreiro e do reisado foram exaustivamente trabalhados. É importante destacar também que essas danças eram totalmente desconhecidas pela maioria dos alunos, conforme comentários dos mesmos ao final da aula.

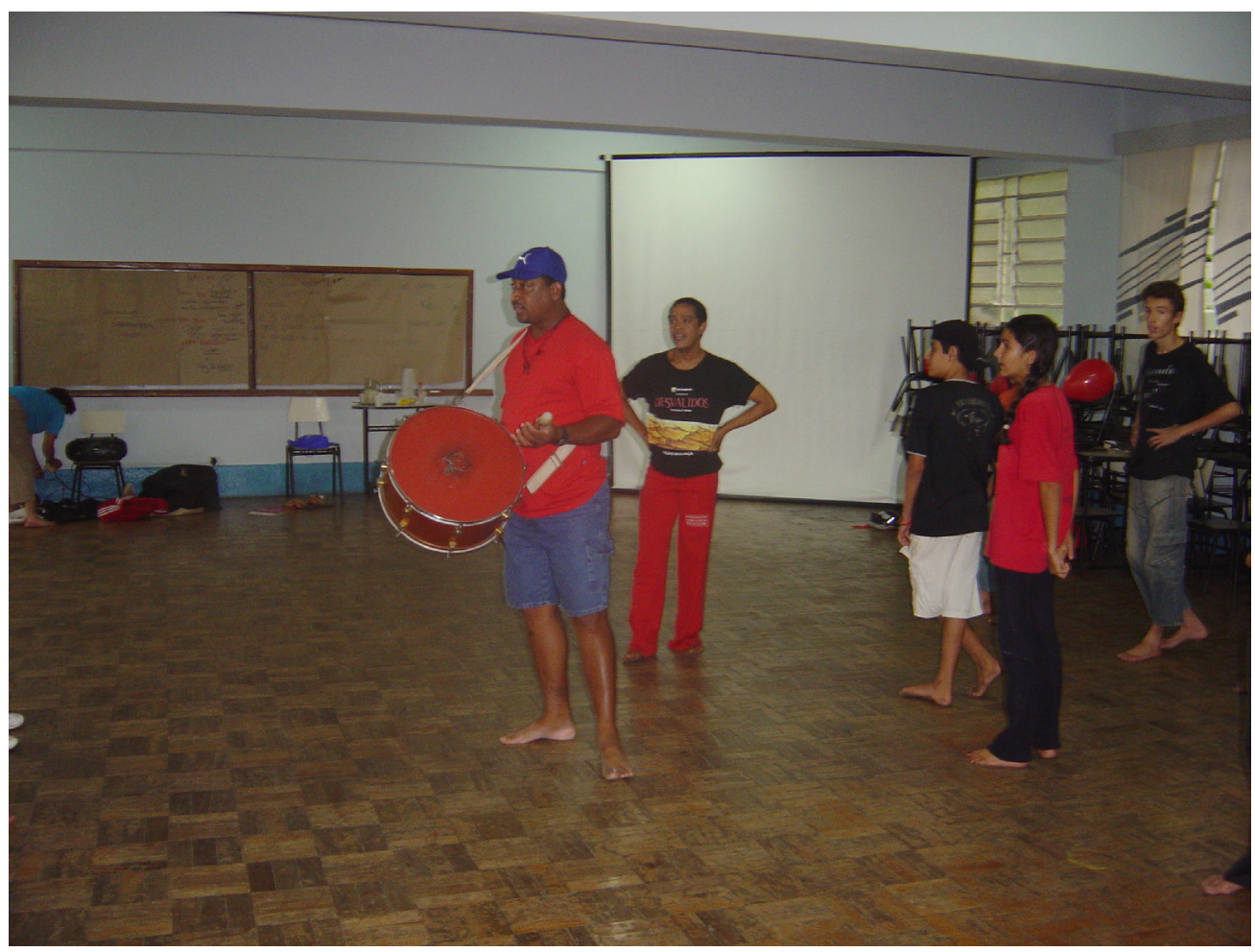

Figura 2 - Aprendendo o ritmo: Observam-se no centro do espaço os atores Tonhão, com a zabumba, e Iradilson ensinando o ritmo das danças do guerreiro e do reisado aos alunos (12/11/05). Local: Salão paroquial, Itaúna, Minas Gerais. Fonte: Foto de Narciso Telles. 
Os reisados e guerreiros são as duas festas mais trabalhadas pelo Grupo Imbuaça em suas oficinas teatrais.

O reisado, segundo Câmara Cascudo (1984), que deriva de "reis", foi uma masculinização brasileira da palavra portuguesa "reisada", cujo significado é rapaziada ou patuscada, coisas próprias de rapazes ou de patuscos, farra ou ajuntamento festivo com dança e canto.

Essa festa, no entanto, encontra em todo o território brasileiro e, mesmo entre os folcloristas, uma série de variáveis conforme a região. Numa tentativa de defini-la, Mário de Andrade indica-nos que os reisados - em suas diversas variações - são uma representação dançada e cantada, dividida em três momentos: o cortejo, as embaixadas, que seriam as partes dramáticas e os cânticos de louvação e despedida.

No entendimento de Gomes \& Pereira (1988), o cortejo é o momento da festa de recriação do espaço, no qual a comunidade integra-se ao ritual: "Percorrer caminhos trilhados pelos ancestrais é reviver a força de comunicação com o mundo invisível". (p. 159) Para esses autores, existe uma diferença entre reinado, um dos componentes do congado, por exemplo, e reisado, festa com referência aos Reis Magos.

O guerreiro é uma suposta adaptação do reisado. Conforme indica Douxami (2004), essa é uma manifestação híbrida, formada por elementos dos Autos dos Caboclinhos, rezas de Xangô e figuras míticas. Analisando a festa do ponto de vista teatral, coreográfico e musical, a pesquisadora identifica a estrutura da mesma apontando as seguintes características: a sucessão de "partes" e "entremeios" e a intervenção do Mateus (figura cômica) como elementos teatrais. As danças que sempre acompanham as "partes" e "entremeios" e todo o "espetáculo" são seguidas musicalmente por sanfona, caixa e pandeiros. Essas festividades têm como matriz o conceito de brincar, que "significa literalmente "colocar brincos", isto é, unir-se, suspender as fronteiras que individualizam e compartimentalizam grupos, categorias e pessoas" (DA MATTA, 1981, p. 49).

A noção de brincar, no âmbito da cultura popular, tem uma dimensão de reinventar o mundo, de percebê-lo por meio das danças e brincadeiras, por um outro canal de comportamento, de um exercício de teatralidade. "É também uma espécie de escola, onde se desenvolvem habilidades e técnicas, onde se adquire uma série de conhecimentos e saberes, onde se aprendem valores" (OLIVEIRA, 2006, p. 47).

A articulação dessa pedagogia teatral com a cultura popular nos permite relacionar a atuação dos artistas-docentes em sua atividade na sala de aula, com a noção de brincadeira presente nas manifestações da cultura popular. Em todos os encontros, os atores do Imbuaça propunham para o início das atividades um "aquecimento lúdico" com músicas "folclóricas", e todos os participantes cantavam e brincavam em roda. Como o brincante, os artistas-docentes re-arranjavam o mundo sob a ótica do divertimento, construindo um espaço aberto à criação e ao jogo.

Sobre a apropriação da cultura popular como material recorrente no campo educacional, Henry Giroux afirma: "precisamos reconhecer como a cultura popular pode constituir um campo de possibilidades dentro do qual os alunos podem ser capacitados para se apropriarem das formas culturais em termos que dignifiquem e ampliem suas possibilidades humanas" (GIROUX, 1999, p. 228).

A partir do segundo dia de trabalho (13/11/05), até o final da oficina, as atividades foram ministradas apenas pelos atores Lindolfo Amaral e Tetê Nahas. Os demais membros do grupo, após o primeiro dia, retornaram para Aracaju. Este encontro foi 
iniciado com uma aula teórica de Lindolfo sobre o teatro de rua no Brasil e a literatura de cordel. Foi pontuada a experiência do Teatro Livre da Bahia e o trabalho de João Augusto e Benvindo Siqueira que, segundo Lindolfo, foram os mais expressivos dramaturgos/adaptadores de peças baseadas em folhetos de cordel. Após a explanação, iniciamos a leitura de dois folhetos de cordel: "A propaganda do matuto com um balaio de maxixe", de João Pacheco e "História do boi leitão" ou "O vaqueiro que não mentia", de Francisco Firmino de Paula. A leitura, feita em roda e por todos os participantes da oficina, tinha por objetivo promover o conhecimento do texto e aproximar os alunos da literatura de cordel. Foi interessante perceber durante a leitura como essa estrutura literária possui um ritmo ágil e uma construção métrica bastante precisa, o que muitas vezes dificultava a leitura para alguns.

Após um pequeno intervalo, retomamos o trabalho com as danças sob a orientação de Tetê. Novamente, o reisado e o guerreiro foram a base de todo o trabalho. A cada momento do trabalho uma parte do corpo era escolhida e detalhadamente trabalhada. Posso, a título de exemplo, citar a região inferior do corpo, especialmente os pés, que nas referidas danças possuem uma certa agilidade nos movimentos. Ficamos detidos nos movimentos dos pés: giros para a esquerda e direita, sempre ritmados pelo apito de Tetê. A função exercida pela artista-docente nessa atividade assemelha-se à forma utilizada pelo mestre e/ou capitão nas festas populares. $\mathrm{O}$ uso do apito pelo Capitão, comandando o ritmo e os movimentos, é comum nas danças do reisado e do guerreiro. O som marca o ritmo enquanto o Capitão serve de guia para os brincantes e tocadores. Após esse exercício, a aula foi finalizada com o aprendizado, pelo grupo, da música Um pé de fulô, da região de Itaúna. Improvisamos passos que se tornaram um material utilizado para os encontros seguintes, assim como o aquecimento na rua no último dia. Segundo os oficineiros, a troca de informações culturais é algo fundamental para o Imbuaça. Eles sempre procuram aprender alguma dança e/ou música do local em que ministram essa oficina.

A aula do dia 14/11/05 foi iniciada com a leitura do texto "O barulho de lampião no inferno", de João Augusto, baseado em folheto da literatura de cordel. Após a leitura, Lindolfo apresentou o trabalho de João Augusto ${ }^{3}$ e explicou as principais características de sua dramaturgia:

a) Presença de um cantador/narrador que tem a função de apresentar a história, de construir as ações que vão sendo vivenciadas pelos personagens, e fazer a interlocução com o público.

Vejamos dois exemplos dessas funções na primeira fala do cantador/narrador, na obra trabalhada na oficina:

CANTADOR - Um cabra de Zé Baiano, por nome de Pilão sem Tampa, que morreu em combate na cidade de Sulampa, disse que no inverno, Lampião foi ao inferno: quase que o diabo se campa. Quando ele lá chegou, foi batendo no portão. Um cabra se apresentou - era moleque forte, que não temia a morte, em luta nunca apanhou.

\footnotetext{
3 Lindolfo Amaral desenvolveu uma pesquisa de mestrado junto ao Programa de Pós-Graduação em Artes Cênicas da UFBA sobre a dramaturgia de João Augusto. Cf. AMARAL FILHO, Lindolfo. Na trilha do cordel:a dramaturgia de João Augusto. PPGAC/UFBA, 2005.
} 
Já no momento inicial da peça verificamos tanto a função de apresentador da história, como o primeiro movimento de construção das ações dos demais personagens.

b) Em algumas peças a estrutura cordelesca é mantida, o texto possui um ritmo melódico e a rima em sextilha.

c) Personagens-tipos.

d) Diálogos curtos e constituídos por um ritmo próprio.

Uma outra passagem do texto para exemplificar:

LAMPIÃO - Meu nome é Lampião.

PORTEIRO - Seu nome não tem jeito não. Lamparina ou Lampião?

LAMPIÃO - Eu me chamo Lampião, mas é só de brincadeira.

PORTEIRO - Acabe com esta besteira. Veio aqui me chatear? Onde é que já se viu um homem alumiar?

LAMPIÃO - Quem alumia é o tiro, que eu dou na escuridão. Mato andorinha voando quanto mais gavião. Mato sargento, tenente, coronel e capitão. Cabra da tua marca, mato até de bofetão.

e) Forte presença de contornos cômicos.

f) Temática relacionada aos aspectos cotidianos do povo.

No caso ainda das adaptações dramatúrgicas de João Augusto, o nome e a visão de mundo do autor do folheto são mantidos (AMARAL FILHO, 2005).

A importância dada ao trabalho com essa dramaturgia na oficina de teatro de rua do Imbuaça é notória. Já no título da oficina, a relação entre teatro de rua e literatura (dramaturgia) de cordel é colocada. A discussão em torno da existência ou não de uma dramaturgia própria ou apropriada para teatro de rua é corrente nos encontros, festivais e seminários destinados à apresentação e análise dessa modalidade teatral. Pretendo tecer algumas considerações em torno dessa questão, recortadas a partir de nossa experiência de pesquisa com o Imbuaça.

Podemos verificar três formas de pensar a dramaturgia para teatro de rua: uma primeira, relacionada à ideia de um teatro de rua popular cômico, com vinculações tanto às tradições circenses quanto teatrais de longa duração; uma segunda, fundamentada especialmente, no pensamento de Brecht, que propõe uma dramaturgia épica; e ainda, uma terceira via que localiza a dramaturgia para/do teatro de rua nas possibilidades de relação da obra com o espaço urbano.

O Imbuaça está localizado no primeiro grupo, que utiliza em seus espetáculos de rua um material dramatúrgico cômico-popular que se insere na longa tradição do teatro cômico no ocidente. Essa dramaturgia, que pelas características elencadas anteriormente, promove uma comunicação mais direta com seu público e propicia, dessa maneira, o estabelecimento de uma relação de empatia entre os espectadores e a audiência.

Paralelamente ao trabalho, leitura e compreensão do texto, continuávamos desenvolvendo o trabalho de ritmo e movimento. Mais familiarizados com as danças, a oficineira ia passo a passo introduzindo novos elementos, como, por exemplo, o uso do bastão junto com o movimento do guerreiro. Duas filas, uma de frente para outra, e um bastão para cada participante. Ao chegar na ponta da fila, os dois "guerreiros" iniciavam 
um duelo com os bastões executando o passo "tesoura" (cruzamento das pernas) da dança, no ritmo dado pelo apito. Além do corpo em ação, esse exercício nos pedia um grau de atenção e precisão intenso, pois, para o bom termo do exercício, era necessário sincronicidade entre os pares, além de ritmo e coordenação motora.

Outro trabalho desenvolvido nesse dia foi a dança com os bastões. No espaço de trabalho, organizamos duas filas, uma de frente para outra, e os atores, em duplas, no ritmo do movimento (no caso, o reisado) iam cruzando as pernas e pés e, concomitantemente, batiam os bastões - pontas superior e inferior -, num movimento ininterrupto até o final da fila. Com essa atividade, eram trabalhados a atenção, a precisão, o tempo-ritmo, a coordenação motora e a manipulação do bastão. Marcando o ritmo do movimento, ao fundo, vemos a artista-docente no apito e uma aluna no bumbo. À medida que os participantes iam dominando a atividade, o ritmo ia sendo gradativamente acelerado, de modo a aumentar o grau de atenção necessária para o trabalho.

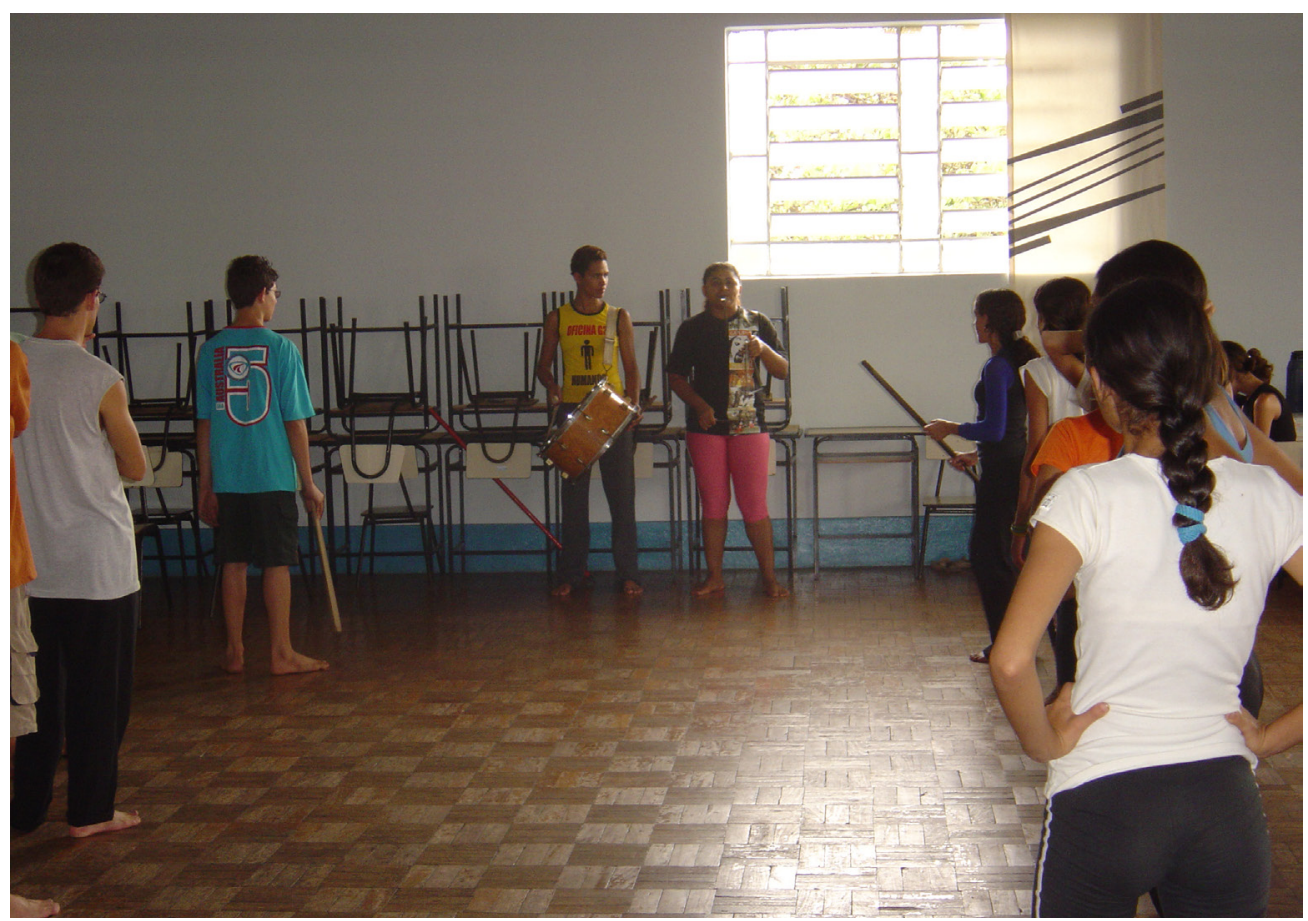

Figura 3 - Bastão e movimento: Nota-se a disposição para o exercício ser desenvolvido. Ao fundo, Tetê Nahas, com o triângulo e apito, e acompanhada por uma aluna da oficina na zabumba, marca o ritmo do trabalho. Ao centro, dois alunos fazendo o exercício: bastão e movimento. Na lateral, as duas filas paralelas onde estão os demais participantes. (14/11/05). Local: Salão paroquial, Itaúna, Minas Gerais. Fonte: Foto de Narciso Telles.

O uso do bastão para desenvolver os domínios necessários ao trabalho do ator é algo comum no treinamento e nos processos formativos de vários grupos e artistas. Referindo-se ao trabalho com objetos, como bastão, diz Burnier: "esse treinamento visa desenvolver uma relação ator-objeto onde os impulsos das ações do ator são transportados para o objeto, e a dinâmica espacial do objeto é transferida para o corpo do ator" (2001, p. 117). 
No caso do Imbuaça, o bastão foi o objeto trabalhado na sequência de atividades de movimento e ritmo, ocorridas desde o primeiro dia de oficina. Não houve nenhum trabalho individual com o objeto, de forma que o ator criasse cenas ou dinâmicas próprias, mas esse foi acionado coletivamente, já que, ainda na fila, os participantes já faziam o passo "valsinha" - movimento para frente e para trás em compasso ternário simples (ritmo de valsa) - com o bastão na mão, mantendo o ritmo que só era alterado no momento do "encontro dos bastões". O ritmo de trabalho com o objeto era dado pelo artista-docente e variava no decorrer dos exercícios: momentos de ritmo mais lento e momentos mais acelerados. Podemos verificar aqui pontos relacionados à transposição didática dos procedimentos acionados, recompondo variações a partir das referências matrizes: o ritmo do folguedo sofre variações não constantes na tradição, para o atendimento da atividade pedagógica.

Para mim, na qualidade de pesquisador-participante nesse processo, é importante relatar o grau de dificuldade e de complexidade do exercício, no que se refere à coordenação de partes do corpo para dinâmicas diferentes de ações: pernas cruzando, movimentos de braços alternando as batidas no bastão, no mesmo ritmo e nas variações impostas pelo andamento musical. É interessante notarmos como o exercício possibilita acessarmos um conjunto de informações corpóreo-sensoriais no decorrer da atividade, e nos mostra como este processo de transposição didática, a partir de elementos encontrados nas manifestações populares, torna-se um rico acervo a ser mobilizado pelos artistas-docentes.

Após essa atividade, a turma já aquecida, foi dividida em dois grupos que escoIheram um dos folhetos de cordel lidos ou o texto de João Augusto para ser trabalhado e apresentado na rua no último dia da oficina. Por indicação dos oficineiros, não participei desse trabalho. Fiz apenas a observação dos grupos. O objetivo era trabaIhar a cena em roda, de forma que os alunos pudessem experimentar essa forma de organização do espaço a partir do material dramatúrgico.

Nos exercícios propostos na oficina para o trabalho em roda, identificamos a transposição didática do projeto estético do grupo. Nas atividades, o material dramatúrgico, com um alto grau de comicidade e tipificação dos personagens, os elementos já mencionados da cultura popular e a forma de ocupação do espaço mais utilizada pelo Imbuaça em seus espetáculos eram trabalhados de forma integrada.

Cada grupo de alunos, sob a coordenação de um oficineiro diferente, começou um trabalho de improvisação e criação das cenas. A cada momento do trabalho, os professores davam explicações ou demonstrações de procedimentos de atuação em roda, organizando todo o material levantado pelas improvisações. Num primeiro tratamento da dramaturgia pelos alunos, o aspecto cômico da mesma foi ressaltado. Cabe mencionar que quase todos os alunos haviam assistido ao espetáculo apresentado pelo Imbuaça no qual tal aspecto foi bastante pontuado na encenação. Informações técnicas como a movimentação na roda, o triângulo no jogo entre os atores, a projeção vocal e o próprio ritmo do texto foram exercitados nesse trabalho. 


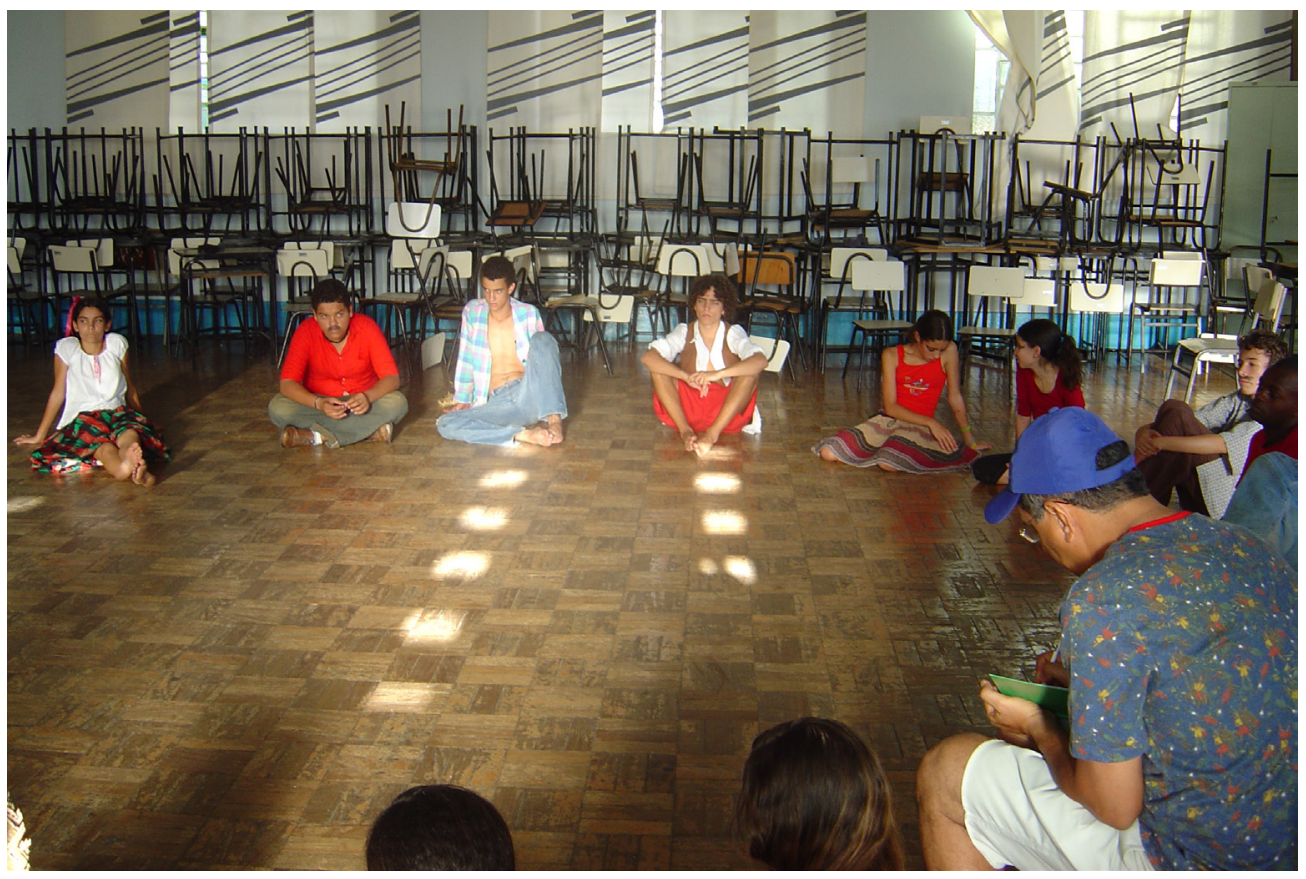

Figura 4 - Aprendendo o ritmo: Os alunos em roda, após realização do trabalho cênico, ouvindo os comentários de Lindolfo Amaral Filho - à frente, à direita (14/11/05). Local: Salão paroquial, Itaúna, Minas Gerais. Fonte: Foto de Narciso Telles.

A roda, desenhada no chão da sala de trabalho, foi explorada em todas as suas possibilidades: movimentações do ator no sentido horário e anti-horário, nas bordas e no eixo, com variações de tempo e ritmo; realização de movimentação triangular, com três alunos se movimentando no interior da roda, ocupando os espaços vazios pela relação entre eles; a contracenação aberta, estabelecendo uma relação não distanciada com o público, mas sim uma relação cúmplice, de forma que esse mantivesse um elo com a história contada. Sobre a disposição do público em roda, valemos das observações de Guénoun: "[o círculo] é precisamente a estrutura que permite que as pessoas se vejam e distingam as demais não como massa, mas como reunião de indivíduos: permite ver os rostos - reconhecer-se" (GUÉNOUN, 2003, p. 20-21).

Esse trabalho, que perdurou por todo o período vespertino, aproximadamente quatro horas sem intervalo, foi bastante útil para o grupo de alunos. Era visível que após cada comentário, a cena adquiria um desenho mais preciso e com maior vitalidade e os atores, um aprendizado técnico. Lindolfo e Tetê assistiam a cada passada da cena, intervindo quando era necessário trabalhar detalhadamente com um ator ou com o conjunto. Ao final do trabalho, em roda, todos teceram comentários do que viram e experenciaram.

A utilização da roda em espetáculos teatrais de rua, em especial naqueles que explicitamente relacionam elementos de sua prática artística com a cultura popular tradicional, é de fato algo bastante comum. Esta forma de organização espacial constrói uma estrutura espacial que, no sentido arquitetônico, destaca o fenômeno teatral do movimento social da cidade, e pode possibilitar uma certa sensação "cujo poder se exerce sem limites fixos, num espaço infinitamente aberto e livre" (SOURIAU, s/d, p. 36). 
Um ponto a ser analisado é a relação que esse coletivo estabelece entre comicidade, personagens tipificados e a roda. Essa relação está, numa primeira instância, vinculada a uma concepção de teatro de rua como popular, no sentido de que o tema e a forma de apresentação se revelem ao espectador, proporcionando uma maior integração deste ao espetáculo por meio do riso e da narrativa apresentada. Assim, a conjugação de uma dramaturgia de fortes traços cômicos, com personagens "identificáveis facilmente pelo público" (SOUZA, 1993, p. 228) e uma forma de organização espacial que acolhe e protege o espetáculo teatral da dinâmica cotidiana da cidade, garante uma intensa comunicação com o público heterogêneo e não convocado de transeuntes.

Numa segunda instância, a relação se pauta no material dramatúrgico escoIhido, selecionado e acionado pelo grupo em seus espetáculos de rua e utilizado como conteúdo das oficinas. A dramaturgia de cordel reelabora aspectos das manifestações culturais populares, "ligadas às correntes de longa duração (que envolvem persistências e variações), à transmissão oral, à hegemonia da festa, à mistura entre o sagrado e o profano, ao rústico, à eleição de praças e ruas como espaço de intenso convívio entre manifestações artísticas, ao riso" (RABETTI, 2000, p. 4). Isso impõe um modo de criação artística com métodos específicos que dialoguem com as faixas culturais diversas, e, no grupo em questão, no estabelecimento desta tríade: comicidade, personagens tipificados e a roda, como marcos que definem a seleção de procedimentos de atuação a serem ensinados/experienciados na oficina de teatro de rua, utilizando a literatura de cordel.

Como nos dias anteriores, iniciamos o encontro seguinte (15/11/05) com um aquecimento coletivo, com as danças/movimentos e músicas aprendidas durante a oficina. Em seguida os dois grupos começaram a organizar o material para o ensaio da cena trabalhada, na rua (Praça da Matriz). Lindolfo e Tetê organizaram um pequeno roteiro para o trabalho, que também incluía danças e músicas. Neste dia minha participação foi de "observador", já que não havia, por sugestão dos oficineiros, participado do processo de criação da cena pelo grupo. Fomos todos para a praça e, lá chegando, escolhemos o local mais adequado para o exercício, levando em conta o fluxo de transeuntes. Vale registrar que essa atividade teve como público alguns integrantes do Grupo Galpão que estavam também participando, nesse dia, do Festival. Sobre o exercício em si, destacamos a importância, para uma oficina de teatro de rua, de atividades nos espaços da cidade e com a presença de "público acidental". Mesmo com toda a inexperiência de alguns alunos, as cenas ganharam uma vitalidade até então inexistente, assim como o trabalho com a roda também ganhou força. Ficamos na praça por aproximadamente uma hora, nesse trabalho que finalizou a oficina. Depois retornamos à sala de trabalho para uma avaliação de todos os dias e uma pequena confraternização.

Como podemos notar, a pesquisa de campo mostrou-se fundamental para a compreensão da metodologia de ensino/formação de atores para teatro de rua desenvolvida pelo Grupo Imbuaça. Um aspecto a ser destacado diz respeito à constituição e à consolidação de um projeto artístico e pedagógico no decorrer de sua trajetória, que leva necessariamente a um processo de especialização atorial. Esse gradativo processo de especialização é comum em diversos coletivos, como verifiquei nos demais grupos analisados em minha pesquisa. Os vínculos de identificação ao projeto teatral já definido, no caso deste grupo, se relacionam às matrizes da cultura popular. Para Lindolfo Amaral Filho: 
Nosso ideal é hoje [que] cada ator deva se especializar numa área, e dividir com o elenco sua especialização. Por exemplo: o Tonhão domina ritmo, música e percussão, ele está se especializando nisso. Eu agora estou tendo que me aprofundar em dramaturgia. Tetê e Iradilson se responsabilizam pelo trabalho de corpo, enquanto Isabel tem se dedicado muito a estudar a brincadeira, o jogo ${ }^{4}$.

Nas aulas, os oficineiros assumem na relação de ensino-aprendizagem uma postura de orientador/coordenador, cumprindo a função de "propor e orientar a realização de experiências que vão sendo executadas e testadas pelos alunos" (KEISERMAN, 2004, p. 343).

Um segundo ponto a ser ressaltado diz respeito ao conteúdo e à estrutura da oficina, que estão fundamentados em manifestações da cultura popular tradicional brasileira. As danças do reisado e do guerreiro, os folhetos de cordel, a roda e o cortejo constituem-se não só no material a ser trabalhado em aula por meio dos exercícios e atividades propostas, mas constituem a própria estrutura da aula, como, por exemplo, o posicionamento dos alunos em roda para o desenvolvimento do trabalho. Tal escolha está relacionada ao campo de pesquisa estética que o grupo vem construindo ao longo de sua trajetória, baseada em elementos da cultura popular sergipana.

A organização dos alunos em roda é algo frequente nas oficinas e cursos de teatro. Essa disposição espacial possibilita uma reconfiguração da relação entre professor-aluno. Miranda (2002) acentua que essa forma circular favorece uma constante circulação de posições e funções do grupo no decorrer do trabalho, o que favorece a coletivização.

No caso desta oficina a roda é algo presente na maioria dos espetáculos de rua do Imbuaça e é assimilada pelo grupo como forma essencial de organização do espaço de trabalho, tanto em seu desdobramento espetacular, quanto pedagógico.

Uma especificidade dessa oficina é a articulação de conteúdos teóricos e práticos. Se, normalmente, as oficinas de teatro constituem-se como uma metodologia de ensino voltada primordialmente para o ensino ativo ou prático, a oficina do Imbuaça ocupa, nesse aspecto, um lugar diferenciado. No caso da oficina de teatro de rua através da literatura de cordel, notamos uma articulação entre as questões práticas e teóricas durante as aulas. Mesmo com maior ênfase no fazer prático, essa estratégia metodológica de ensino, no nosso entender, relaciona-se com a experiência pessoal dos atores do grupo, como alunos do Programa de Pós-Graduação em Artes Cênicas da Universidade Federal da Bahia (UFBA), que desenvolvem pesquisas relativas à trajetória e à estética do grupo.

Tomando o conceito de experiência como um possível caminho de enfrentamento da "tensa" relação entre prática e teoria no ensino, na pesquisa e na prática teatral, consideramos, pela análise empreendida em torno da didática do Imbuaça, que esses artistas-docentes desenvolvem e articulam suas práticas no sentido que De Marinis (2012) aponta como uma "experiência-compreensão do artista de teatro". Esta se caracteriza como uma "competência ativa, mais ou menos explícita". Conforme comentamos, esta tipologia amplia o leque para o entendimento das relações possíveis entre a prática e a teoria teatral em sua complementaridade e em seus espaços de tensionamentos.

4 Entrevista realizada por Narciso Telles com Lindolfo Amaral. Itaúna, 2005. 
No Imbuaça, pretende-se uma articulação entre estes dois campos, tal como se apresentou durante os encontros da oficina, favorecendo aos alunos envolvidos o aprendizado de um conhecimento-compreensão ancorado num saber-fazer tecido de fortes relações com a cultura popular.

\section{Referências}

ABREU, Martha. Cultura popular; um conceito várias histórias. In: ABREU, Martha; SOIHET, Raquel (orgs). Ensino de história: conceitos, temáticas e metodologias. Rio de Janeiro: Casa da Palavra, 2005. p. 83-103.

AMARAL FILHO, Lindolfo. Na trilha do cordel: a dramaturgia de João Augusto. Salvador, 2005. Dissertação (Mestrado em Artes Cênicas), Programa de Pós-Graduação em Artes Cênicas, UFBA, 2005.

ANDRADE, Mário. Danças dramáticas do Brasil. Belo Horizonte: Editora Itatiaia, 1982.

BURNIER, Luís Otávio. A Arte do ator: da técnica à representação. Campinas: UNICAMP, 2001.

CASCUDO, Câmara. Dicionário do folclore brasileiro. Rio de Janeiro: Ediouro, 1984.

DA MATTA, Roberto. Carnavais, malandros e heróis: para uma sociologia do dilema brasileiro. Rio de Janeiro: Rocco, 1981.

DOUXAMI, Christine. O estudo fílmico e antropológico do Guerreiro: primeiras reflexões. Cadernos GIPE-CIT, Salvador, n. 11, p. $58-73$, jan. 2004.

GIROUX, Henry A. Cruzando as fronteiras do discurso educacional: novas políticas em educação. Porto Alegre: ArtMed, 1999.

GOMES, Núbia Pereira Magalhães; PEREIRA, Edmilson de Almeida. Negras raízes mineiras: os Arturos. Juiz de Fora: Ministério da Cultura, EDUFJF, 1988.

GUÉNOUN, Denis. A exibição das palavras. Uma idéia (política) do teatro. Rio de Janeiro: Teatro Pequeno Gesto, 2003. (Série Ensaios, 1)

KEISERMAN, W. Nara. Caminho pedagógico para a formação do ator narrador. Rio de Janeiro, 2004. Tese (Doutorado em Teatro), Universidade Federal do Estado do Rio de janeiro (UNIRIO) - Centro de Letras e Artes, Programa de Pós-Graduação em Teatro, 2004.

MARINIS, Marco de. Ter experiência em arte: para uma revisão das relações teoria/prática no contexto da nova teatrologia. In: TELLES, Narciso (org.). Pesquisa em Artes Cênicas: textos e temas. [S.I.]: e-papers, 2012. p. 35-44.

MIRANDA, Brígida. Uma estrutura circular para o treinamento físico de atores. Urdimento, Revista de estudos sobre teatro na América Latina, Florianópolis, n. 5, p. 110-116. 2003. 
OLIVEIRA, Mariana S. O jogo de cena do Cavalo Marinho: diálogos entre teatro e brincadeira. Rio de Janeiro, 2006. Dissertação (Mestrado em Teatro) - Centro de Letras e Artes. Programa de Pós-Graduação em Teatro, UNIRIO, 2006.

RABETTI, Maria de Lourdes (Beti Rabetti). Memória e culturas do popular no teatro: o típico e as técnicas. O Percevejo, Universidade Federal do Estado do Rio de Janeiro (UNIRIO); Centro de Letras e Artes; Escola de Teatro; Departamento de Teoria do Teatro; Programa de Pós-Graduação em Teatro, n. 8, p. 3-18. 2000 .

SOURIAU, Etienne. O cubo e a esfera. In: REDONDO JÚNIOR. O teatro e sua estética. Lisboa: Arcádia, s/d. p. $31-54$.

SOUZA, Eliene Benício de. Teatro de rua: uma forma de teatro popular no Nordeste. São Paulo, 1993. Dissertação (Mestrado em Artes), Escola de Comunicação e Artes, Programa de Pós-Graduação em Artes. ECA/USP, 1993.

TELLES, Narciso. Pedagogia do teatro e o teatro de rua. 2. ed. Porto Alegre: Mediação, 2013. 